\title{
The use of a robotic gait simulator for the development of an alignment tool for lower limb prostheses
}

\author{
Eveline De Raeve ${ }^{1 *}$, Tom Saey ${ }^{1}$, Luiza Muraru ${ }^{1,2}$, Louis Peeraer ${ }^{3}$ \\ From 4th Congress of the International Foot and Ankle Biomechanics (i-FAB) Community \\ Busan, Korea. 8-11 April 2014
}

\begin{abstract}
Aim
An innovative tool to optimise the configuration and alignment of lower leg prostheses based on individual comfort needs of the patient will be developed in this project.
\end{abstract}

\section{Background}

This tool meets the demand of prosthetists to optimise and objectify the dynamic alignment of transtibial prostheses. Nowadays, the prosthetists mainly rely on their own expertise and experience.

Current methods to align the prosthesis start with a static alignment of transtibial prosthesis. This method does not take the individual patient comfort into account. Afterwards, adjustments to the alignment are done by trial and error. This is a time-consuming and exhausting activity for both prosthetist and patient.

\section{Methods}

10 amputees were asked to walk with 20 different alignments and a neutral alignment (Figure 1A). The effect on comfort was questioned and measured. Therefore ground reaction force, 3D movement of the foot, the shank, upper leg, pelvic and torso and muscle activity were recorded with a force plate (AMTI), a motion tracking system (Codamotion) and EMG-sensors (Delsys). Simultaneously, contact pressure between stump and socket was recorded on 32 reference points with pressure sensors (mFLEX). All data was recorded synchronously at $200 \mathrm{~Hz}$.

Subsequently, the 3D movement of the shank was recalculated to Euler angles to be used as kinematic input for an industrial robot with 6 degrees of freedom

\footnotetext{
* Correspondence: Eveline.DeRaeve@thomasmore.be

1 MOBILAB, University College Thomas More, Geel, Belgium

Full list of author information is available at the end of the article
}

(KUKA) (Figure 1B). An energy consumption system with spring enables us to simulate kinematic and kinetics of prosthetic gait. To objectively measure the pressure, an artificial stump was developed to connect the lower limb prosthesis to the robot (Figure 1C). This artificial stump, which consists of SLS-3D printed bones and soft tissue (silicon) allows us to objectively measure the pressure between stump and socket.

For different alignments, forces (AMTI), motion trajectories and contact pressure between stump and socket (mFLEX) were registered simultaneously during the unroll of the prosthetic foot. These measurements are translated into comfort parameters during postprocessing.

\section{Results and discussion}

Using our robotic gait simulator, the effect of prostheses alignment on patient comfort is mapped. The biggest advantage of this approach is the possibility to test numerous and extreme alignments, without the need for test subjects. After validation with gait analyses, this data is translated in an algorithm which will be converted into a useful method as a tool for the prosthetist.

The outcome of this project will lead to an improved efficiency and effectiveness of the alignment process, and contribute to the quality of life of the amputee.

\section{Trial registration}

Clinical Trial Center - CTC 55509.

\section{Acknowledgments}

This study is funded by TETRA IWT-Vlaanderen (project Ticoon-IWT120144).

\section{Authors' details}

${ }^{1}$ MOBILAB, University College Thomas More, Geel, Belgium. ${ }^{2} \mathrm{BMe}$

Department of Mechanical Engineering, KU Leuven, Leuven, Belgium. 


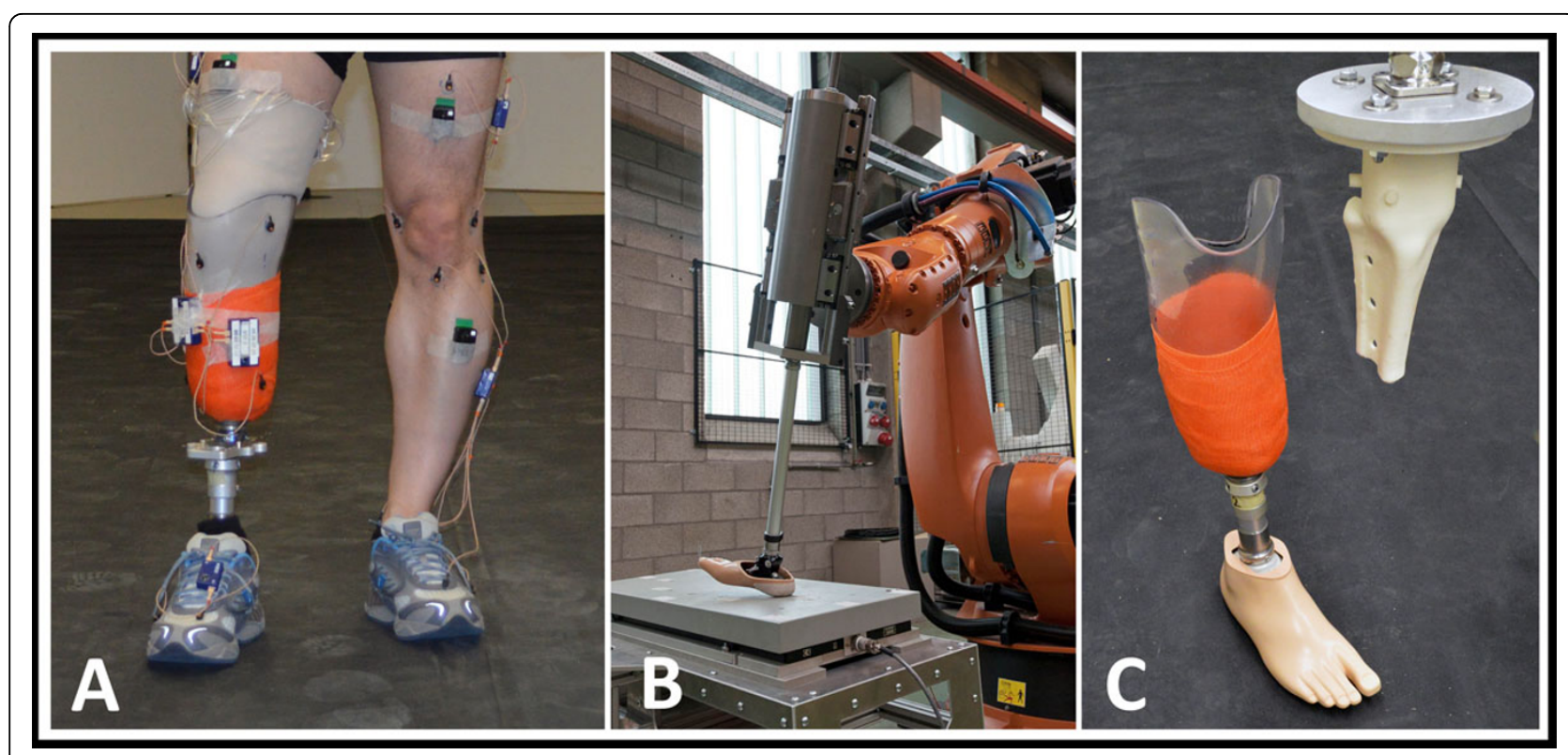

Figure 1 A. gait analyses of an amputee, B. robotic gait simulator, C. artificial stump

${ }^{3}$ Faculty of Kinesiology and Rehabilitation Sciences, KU Leuven, Leuven, Belgium.

Published: 8 April 2014

doi:10.1186/1757-1146-7-S1-A15

Cite this article as: De Raeve et al: The use of a robotic gait simulator for the development of an alignment tool for lower limb prostheses. Journal of Foot and Ankle Research 2014 7(Suppl 1):A15.

Submit your next manuscript to BioMed Central and take full advantage of:

- Convenient online submission

- Thorough peer review

- No space constraints or color figure charges

- Immediate publication on acceptance

- Inclusion in PubMed, CAS, Scopus and Google Scholar

- Research which is freely available for redistribution 